\title{
A FEAST FOR RATS: OLD JAPANESE PRINT
}

Their leader-almost a shepherd!-

Cascades the precious manuscripts, the scrolls, The pile of books that fan out, stairways In a bombing,

And presses his bubonic mouth

To history or literature, taking from them

A jagged kiss to soothe his gums

And carry off like a princess.

The ruck of scions fawning in his disregard Nip out a character or place crinkled feet On the fine hand someone wrote in But an hour before

In the revery of twilight-wrote destined For total darkness. They do not know What to take and what to leaveSo just a taste!

The temple bell rings a swath down the wall. The thunder ... it is late. The gross one turns Lustrous eyes sewerward: off!

To his sepulchral abbey, with scraps. 